\title{
Constant Current Models of Brushless DC Motor
}

\author{
Krzysztof Krykowski (Professor, Silesian University of Technology), \\ Janusz Hetmańczyk (Associate Professor, Silesian University of Technology)
}

\begin{abstract}
Two constant current models of Permanent Magnet Brushless Direct Current Motor (PM BLDC) are presented in the paper. In the first part of the paper principle of operation, basic properties and mathematical equations describing PM BLDC models are given. Then, two different constant current models of PM BLDC motor are considered: In the first model, PM BLDC motor is approximated with dc motor; in the second model, modified constant current model is applied with additional block, which is used to take into account the impact of inductance on torque-speed characteristics. In order to verify these models, torque-speed characteristics have been determined and compared for different motor supply voltages. After running a series of simulation and laboratory tests, we have found that this modified model (which makes allowance for the influence of inductance on torque-speed characteristics) ensures obtaining torque-speed characteristics identical to those of the real motor. Therefore, this model may be recommended for those simulation tests which do not consider effects occurring inside the electronic commutator-motor circuit. However, approximation of PM BLDC motor with de motor is not recommended in computer tests.
\end{abstract}

Keywords - Permanent magnet machines, brushless machines, analytical models, mathematical model, MATLAB.

\section{INTRODUCTION}

Use of computer modeling and simulation has significantly facilitated the processes of analysing power electronics and electromechanical systems together with their synthesis and structural design. Nowadays mostly universal and commercial software is used for modeling and simulation, and in particular Matlab and Simulink package is most often applied.

Models of brushless dc motor with permanent magnets and electronic commutation (usually denoted as PM BLDC motor) have been investigated. In comparison with commutator-type motors they are characterized by higher efficiency, smaller dimensions, longer life-time and higher overload capacity $[6,11]$. Drive systems with PM BLDC motors are extensively used in small and medium power appliances [7, 18]. These motors are used often in model electric vehicles, in dentistry and lots of other devices such as compressors or machine tools $[1,4]$. Work on design of brushless motor with rated speed exceeding $100000 \mathrm{rpm}$ is under way [3, 6, 12].

Permanent Magnet Brushless Direct Current Motor, which is usually abbreviated to PM BLDC, is a synchronous motor operating with (electronic) power electronics converter imitating the action of mechanical commutator. This converter (called also electronic commutator) operates by switching supply voltage between appropriate motor windings at appropriate time instants. The switching is carried out in a discrete manner and their resolution corresponds to number of pulses per one motor revolution. Hence, continuous measurement of rotor position angle is not necessary; it is enough to determine discreetly the time instants when windings should be switched over $[2,5,16,18]$.

Matlab/Simulink software package contains a ready-made PM BLDC model in its library [17]. This model demonstrates motor properties in a faithful enough manner. However, it is characterized by relatively long computing time. This property is especially undesirable when multi-motor drives with PM BLDC motors are simulated. The difficulties caused by long computing time may be by-passed by replacing precise model with functional model, which does not provide exact and detailed information on all effects occurring in the motor; it is limited to showing relationships between current, voltage, load torque and rotational speeds for transient states [9, 13]. Proposal for construction of such model is discussed below.

\section{THE BASIC PROPERTIES OF PM BLDC MOTOR}

The most common circuit of brushless dc motor with permanent magnets and electronic commutator is a threephase motor with star-connected windings and electronic commutator connected into a 3-phase bridge [6, 11, 15].

The connection scheme of main circuit of 3-phase PM BLDC motor with one pole pair, star-connected windings and electronic commutator connected as a 3-phase bridge is shown in Fig. 1. In practice motors with number of pole pairs $p=2-4$ are used most often. If number of pole pairs is equal to $p$, then electrical angular speed and electrical rotor position angle are $\mathrm{p}$ times greater than angular mechanical speed and rotor angle. This is practically the only significant difference between motor with one pole pair and motor with several pole pairs.

Formation of electromagnetic torque curve and EMF and current waveforms for ideal PM BLDC motor, with negligible inductance impact, is shown in Fig. 2. The different phase windings are sequentially switched by bridge transistors and they generate magnetic field characterized by six different field vector positions.

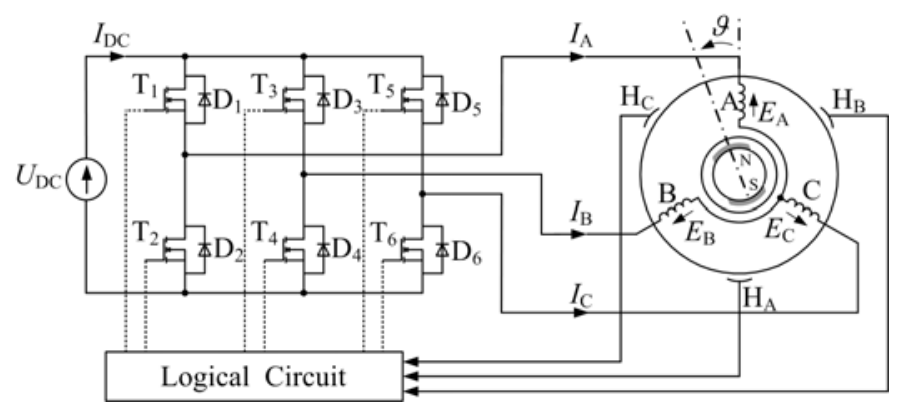

Fig. 1. Electrical connections scheme for 3-phase, 2-pole PM BLDC motor. 
The principle of operation and basic properties of PM BLDC motor are widely described in literature of the subject, for example in references $[11,14,15,18]$. That is why detailed discussion of the motor has not been undertaken in the current paper. The most important relationships describing the motor are set out below:

$$
\begin{gathered}
e_{\mathrm{k}}=\omega K_{\mathrm{fk}}, \\
T_{\mathrm{ek}}=K_{\mathrm{fk}} i_{\mathrm{k}}, \\
T_{\mathrm{e}}=\sum_{\mathrm{k}=\mathrm{A}}^{\mathrm{C}} T_{\mathrm{ek}}, \\
T=T_{\mathrm{L}}+T_{\mathrm{los}}, \\
T_{\mathrm{dy}}=J \frac{d \omega}{d t}=T_{\mathrm{e}}-T .
\end{gathered}
$$

The following designations have been used: $e_{\mathrm{k}}$ - phase electromotive force (EMF), $K_{\mathrm{fk}}$ - excitation coefficient for k-th phase, $T_{\text {ek }}$ - electromagnetic torque generated by k-th phase current, $T_{\mathrm{e}}$ - total electromagnetic torque of the motor, $T, T_{\mathrm{L}}$ and $T_{\text {los }}-$ anti-torque, load torque and motor loss torque, $T_{\mathrm{dy}}-$ dynamic torque, $J$ - total moment of inertia, $\omega$ - angular.

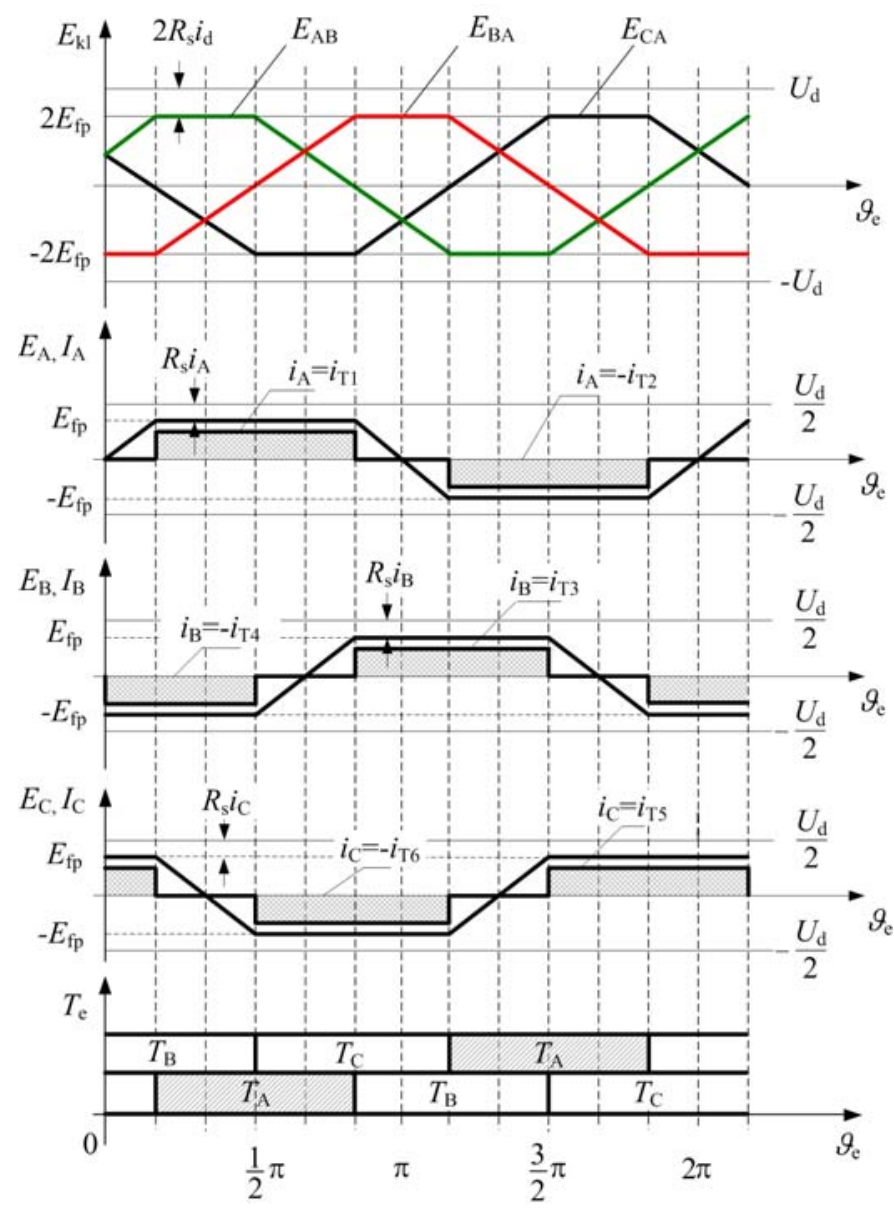

Fig. 2. Phase currents and EMFs waveforms, electromagnetic torque production in ideal PM BLDC motor with square wave phase currents.

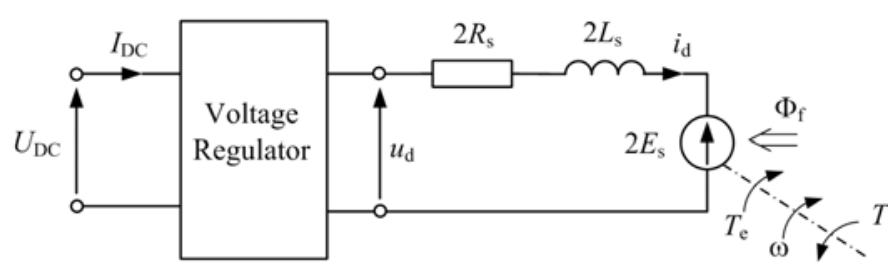

Fig. 3. PM BLDC motor as a special case of dc motor.

The motor with structure shown in Fig. 1 may be developed $[11,14]$ into constant current equivalent model with structure illustrated by Fig. 3. Relationships between current and voltage for this motor may be formulated as:

$$
\begin{aligned}
u_{d} & =2 R_{s} i_{d}+2 L_{s} \frac{\mathrm{d} i_{d}}{\mathrm{~d} t}+2 E_{f p} \\
& =2 R_{s} i_{d}+2 L_{s} \frac{\mathrm{d} i_{d}}{\mathrm{~d} t}+2 K_{f p} \omega .
\end{aligned}
$$

For circuits with dc voltage controller or pulse-width modulation (PWM), the following relationships are true:

$$
\begin{gathered}
U_{\mathrm{d}}=U_{\mathrm{d}^{*}} \cdot U_{\mathrm{DC}}, \\
I_{\mathrm{d}}=\frac{1}{U_{\mathrm{d}^{*}}} \cdot I_{\mathrm{DC}},
\end{gathered}
$$

where $U_{\mathrm{d}^{*}}$ is relative voltage value and $U_{\mathrm{DC}}$ is source dc voltage.

In case of ideal motor with negligible inductance impact, the following relationships are true:

$$
\begin{gathered}
\omega=\frac{U_{\mathrm{d}}-2 R_{\mathrm{s}} I_{\mathrm{d}}}{2 K_{\mathrm{fp}}}, \\
T_{\mathrm{e}}=2 K_{\mathrm{fp}} I_{\mathrm{d}}, \\
\omega_{0}=\frac{U_{\mathrm{d}}}{2 K_{\mathrm{fp}}}, \\
\omega_{0}=\omega_{0}-R_{\mathrm{s}} \frac{I_{\mathrm{d}}}{K_{\mathrm{fp}}},
\end{gathered}
$$

where $K_{\mathrm{fp}}$ is phase excitation coefficient for the flat section of phase EMF waveform.

In real motor, when the windings are switched, the currents do not instantly increase in a step-like manner, but they rise in accordance with exponential curve. This causes emergence of additional voltage drops and increase in slope of torque-speed characteristic. What's more, due to energy recuperation into the source during the time when backward diodes conduct current, the current producing electromagnetic torque $I_{\mathrm{e}}$ is greater than average input current $I_{\mathrm{d}}$ calculated for dc circuit, that is:

$$
I_{\mathrm{e}}=\frac{T_{\mathrm{e}}}{2 K_{\mathrm{fp}}}>I_{\mathrm{d}}
$$

The additional voltage drops may be taken into account by introducing the commutation impact coefficient [11], which provides information on how many times the voltage drop due to commutation is greater than voltage drop across the resistance. 
If we refer to [11], we find that commutation coefficient defined as:

$$
k_{\mathrm{Q}}=\frac{U_{\mathrm{dx}}}{U_{\mathrm{R}}},
$$

will be defined as follows, when slight simplifying assumptions have been adopted:

$$
k_{\mathrm{Q}}=\frac{m p}{2 \pi} \frac{\omega L_{\mathrm{s}}}{2 R_{\mathrm{s}}} .
$$

The most important of all simplifying assumptions is that during commutation motor speed remains approximately constant. When commutation coefficient is used (14), (12) may be reduced to:

$$
\omega=\omega_{0}-R_{s}\left(1+k_{\mathrm{Q}}\right) \frac{I_{\mathrm{e}}}{K_{\mathrm{fp}}} .
$$

When commutation coefficient (15) is introduced into (16), we obtain [2]:

$$
\omega=\frac{\omega_{0}-\frac{R_{\mathrm{s}} I_{\mathrm{e}}}{K_{\mathrm{fp}}}}{1+\frac{m p L_{\mathrm{s}}}{4 \pi K_{\mathrm{fp}}} \frac{T_{\mathrm{e}}}{2 K_{\mathrm{fp}}}}=\frac{\omega_{\mathrm{i}}}{1+k_{\mathrm{l \omega}} I_{\mathrm{e}}}=k_{\omega} \omega_{\mathrm{i}},
$$

where $\omega_{\mathrm{i}}$ is angular speed of ideal motor with negligible inductance impact,

$$
k_{\omega}=\frac{1}{1+k_{1 \omega} \frac{T_{\mathrm{e}}}{2 K_{\mathrm{fp}}}},
$$

is the coefficient of decrease in rotational speed, while

$$
k_{\mathrm{l \omega}}=\frac{m p L_{\mathrm{s}}}{4 \pi K_{\mathrm{fp}}},
$$

is the coefficient of inductance impact on rotational speed of the motor.

The excitation coefficient for the flat section of phase EMF waveform may be determined as:

$$
K_{\mathrm{fp}}=\frac{1}{2} \frac{U_{\mathrm{dn}}}{\omega_{0 \mathrm{n}}}=\frac{30}{2 \pi} \frac{U_{\mathrm{dn}}}{n_{0 \mathrm{n}}} .
$$

\section{Constant Current Mathematical Models OF PM BLDC MOTOR}

Using the above relationships describing ideal PM BLDC motor, a block diagram model may be constructed with structure identical to that of a dc motor. This model $[9,10,11]$ is shown in Fig. 4.

If we want to approximate real motor model with an ideal motor, the output speed should be multiplied by the coefficient of additional slope of $k_{\omega}$ curve, defined by (17). The following formulas result from the law of conservation of energy:

$$
\begin{aligned}
U_{\mathrm{d}} I_{\mathrm{d}} & =T \omega \eta, \\
U_{\mathrm{d}} I_{\mathrm{d} i} & =T \omega_{\mathrm{i}} \eta .
\end{aligned}
$$

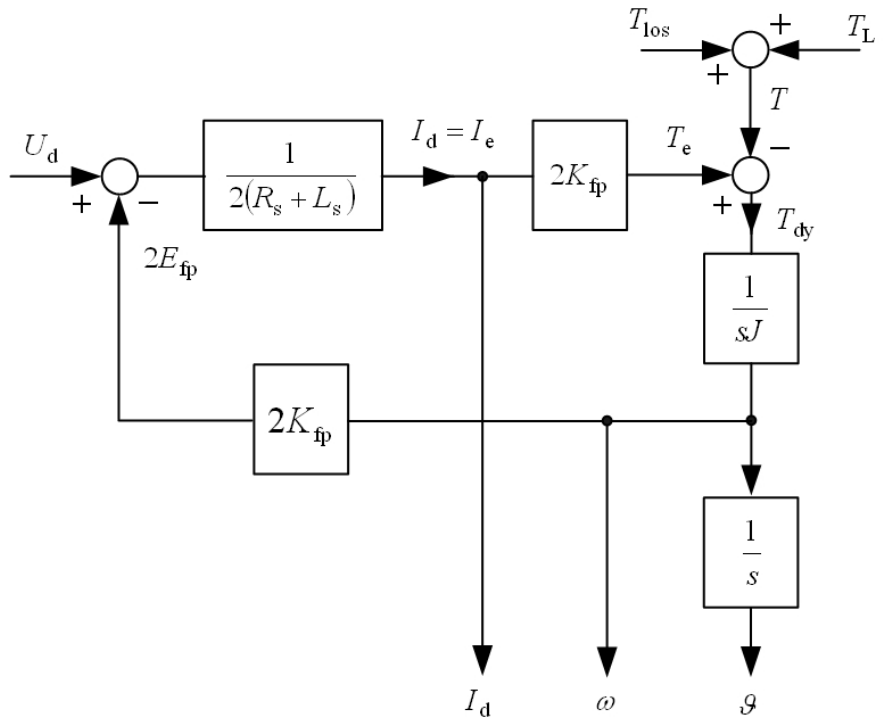

Fig. 4. Constant current model of PM BLDC motor.

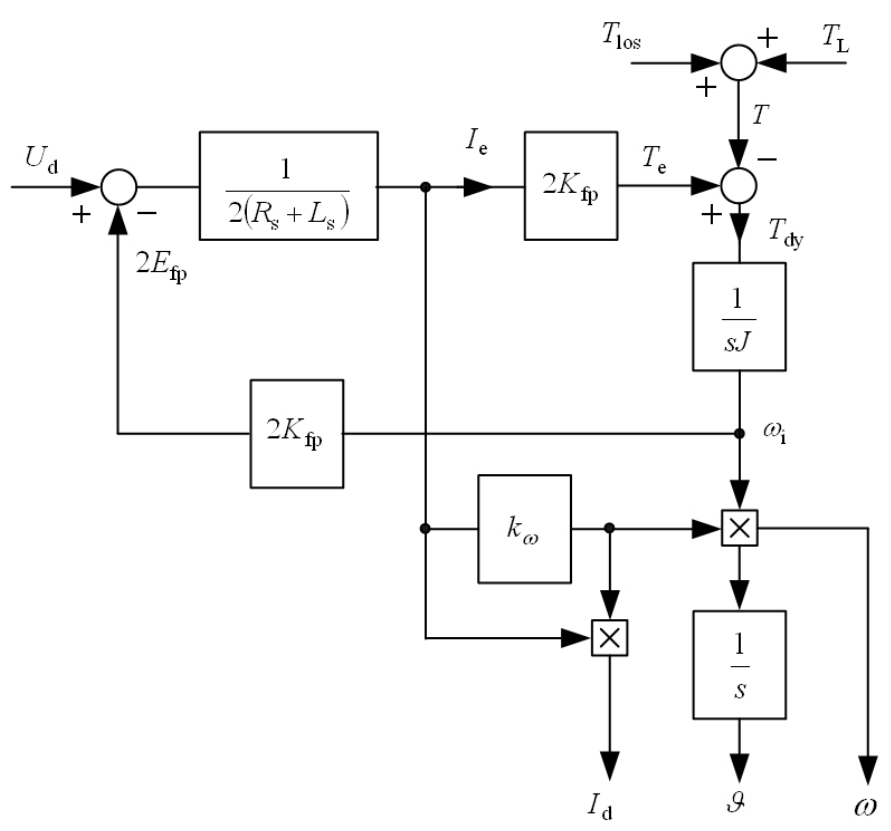

Fig. 5. Modified model of PM BLDC motor, taking into account the impact of inductance.

If it is assumed that motor efficiency is approximately the same for both motors. Taking (16) into account, we obtain the following relationship:

$$
I_{\mathrm{d}}=k_{\omega} I_{\mathrm{di}}=k_{\omega} I_{\mathrm{e}} .
$$

When additional blocks corresponding to (17-19) are introduced into block diagram presented in Fig. 4, the new block diagram is obtained [10]. It is pictured in Fig. 5.

\section{COMPuter Models OF PM BLDC Motor}

Using constant current ideal PM BLDC motor (Fig. 4), a computer model of this motor was constructed within the framework of Matlab/Simulink software [17]. This model together with exemplary waveforms of electromagnetic 
torque T, speed $\mathrm{w}$ and input current $I_{\mathrm{d}}$ are shown in Figs. 6(a) and $6(\mathrm{~b})$. It has been assumed that in the initial time instant the supply voltage changes step-like from 0 to rated value of 24 $\mathrm{V}$. The start-up is carried out with motor loaded with rated torque $T_{\mathrm{n}}$. After $0.15 \mathrm{~s}$ the load torque increases in a step-like manner to double rated value. The presented model does not account for the impact of inductance on motor characteristics.

Modified constant current computer model of PM BLDC motor shown in Fig. 5 corresponds to computer model shown in Fig. 7. This model accounts for the influence of inductance on PM BLDC motor speed and average value of input current. It differs from computer model shown in Fig. 4, since a new coefficient $k_{\omega}$ has been introduced here, which accounts for the impact of commutation on torque-speed characteristics of the motor [11].

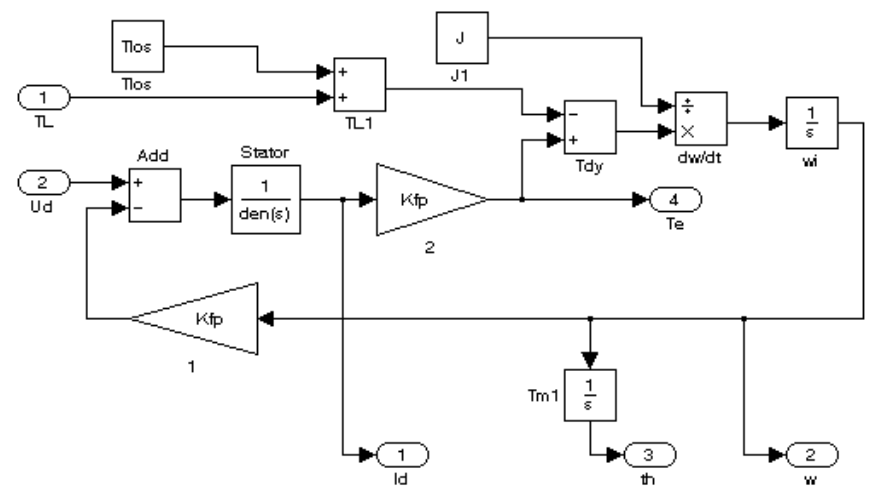

(a)
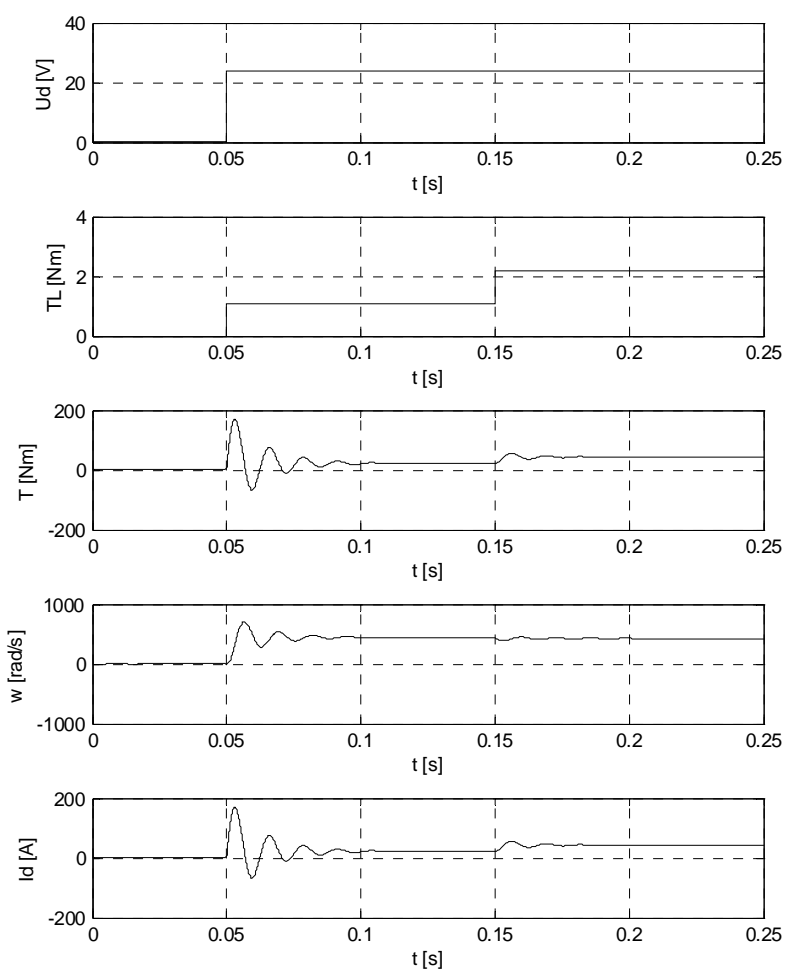

(b)

Fig. 6. Constant current computer model of PM BLDC motor: (a) scheme, (b) waveforms of supply voltage $U_{\mathrm{d}}$, load torque $T_{\mathrm{L}}$, electromagnetic torque $T$, angular velocity $\omega$ and motor current $I_{\mathrm{d}}$.
The waveforms of electromagnetic torque $T$, speed $\mathrm{w}$ and input current $I_{\mathrm{d}}$ obtained under conditions shown in Fig. 6(b) are shown in Fig.7(b); they correspond to the scheme presented in Fig.7(a).

Determination of computer models parameters is demonstrated using a Dunkermotoren company BG75x50 motor tested in laboratory. The selected parameters of this motor (according to catalogue data) are: $U_{\mathrm{dn}}=24 \mathrm{~V}, p=4$, $P_{\mathrm{n}}=431 \mathrm{~W}, I_{\mathrm{dn}} \leq 21 \mathrm{~A}, n_{\mathrm{n}}=3780 \mathrm{rpm}, n_{0 \mathrm{n}}=4660 \mathrm{rpm}, T_{\mathrm{n}}=1,09$ N.m, $L_{\mathrm{s}}=0,125 \mathrm{mH}, R_{\mathrm{s}}=20 \mathrm{~m} \Omega, T_{\mathrm{los}} \leq 0,08$ N.m. Torque constant for this motor is $K_{\mathrm{m}}=52 \mathrm{mN}$.m/A.

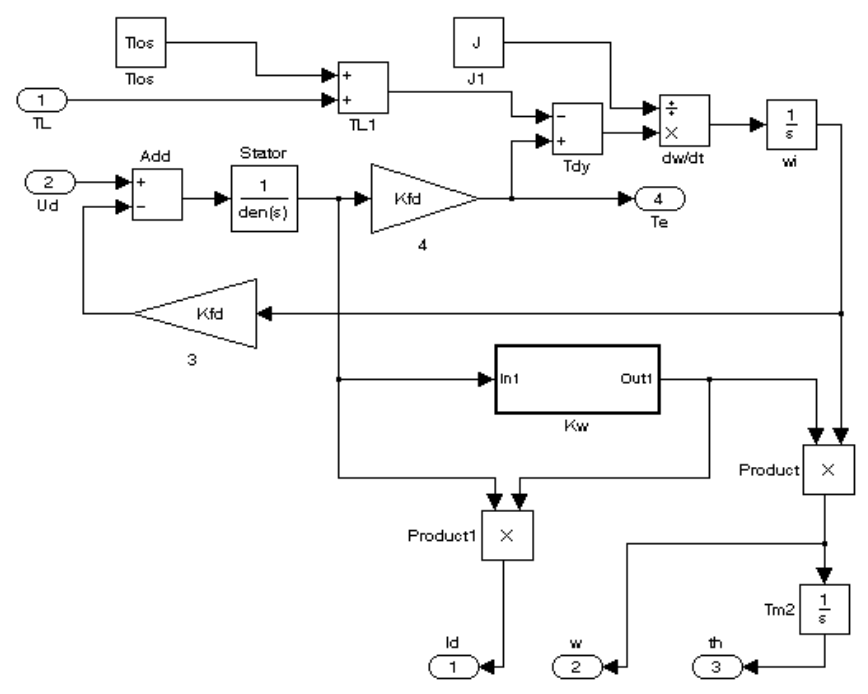

(a)
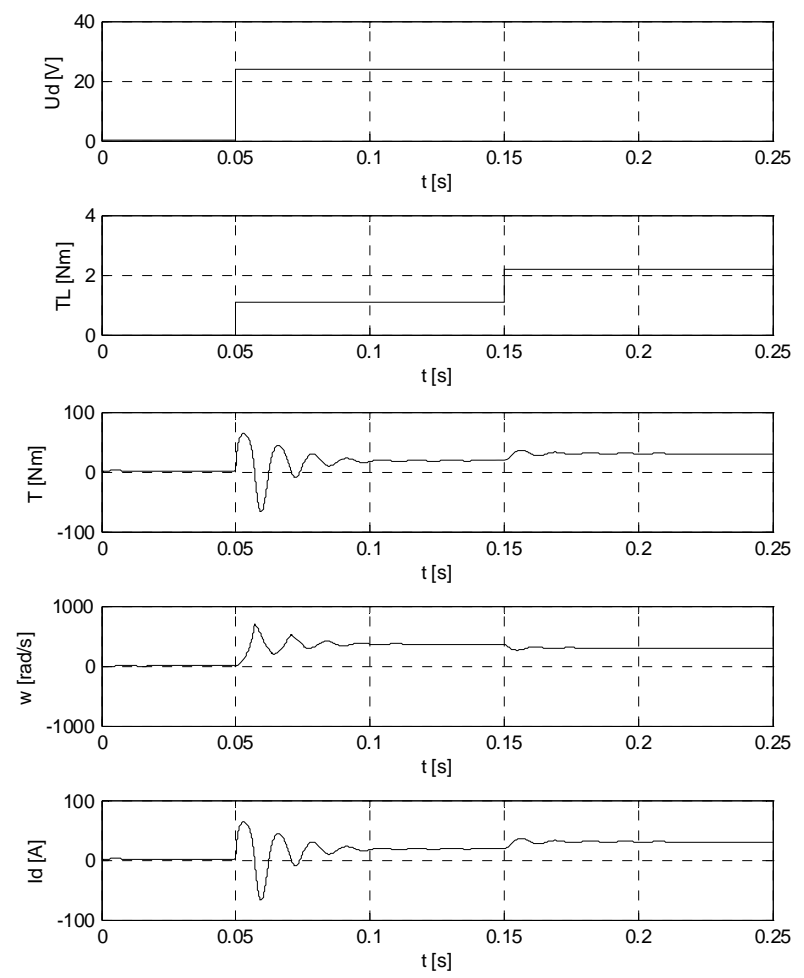

(b)

Fig. 7. Modified computer model of PM BLDC motor with inductance impact taken into account (a) scheme, (b) waveforms of supply voltage $U_{\mathrm{d}}$, load torque $T_{\mathrm{L}}$, electromagnetic torque $T$, angular velocity $\omega$ and motor current $I_{\mathrm{d}}$. 
For the above data, the excitation coefficient for the flat section of EMF results from (20) and is equal to:

$$
K_{\mathrm{fp}}=\frac{1}{2} \frac{U_{\mathrm{dn}}}{\omega_{0 \mathrm{n}}}=\frac{30}{2 \pi} \frac{24}{4660}=24,6 \mathrm{mN} \cdot \mathrm{m} / \mathrm{A} .
$$

The inductance impact coefficient determined from (19) is equal to:

$$
k_{\mathrm{l} \omega}=\frac{m p L_{\mathrm{s}}}{4 \pi K_{\mathrm{fp}}}=\frac{6 \cdot 4 \cdot 0,125 \cdot 10^{-3}}{4 \pi \cdot 24,6 \cdot 10^{-3}}=9,7 \cdot 10^{-3} .
$$

\section{V.SIMULATION AND LABORATORY TESTS}

In order to determine accuracy of proposed models, laboratory and simulation tests of investigated motor have been run. The research has been aimed at comparison of torque-speed characteristics obtained by lab tests and by computer simulations. The investigated PM BLDC motor was loaded with identical PM BLDC motor operating as a brake. The general scheme of the investigated system is shown in Fig. 8.

When determining torque-speed characteristic of the motor, the rotational speed was used. It is related to angular speed in a following way:

$$
n=\frac{30}{\pi} \omega .
$$

The laboratory and simulation tests have revealed significant discrepancies between characteristics obtained for constant current model of PM BLDC motor (shown in Figs. 4 and 6) and real motor characteristics. Therefore, the constant current model of PM BLDC motor with structure as shown in Figs. 4 and 6 cannot be recommended. For modified constant current model of PM BLDC motor (Fig. 7), torque-speed characteristics obtained for investigated motor and its computer model exhibit high convergence. The torque-speed characteristics for modified constant current model of PM BLDC motor obtained in the course of the investigation are shown in Fig. 9.

During calculations it has been assumed that source impedance, transistor and diode resistances and wire impedances are nil. These characteristics have been measured for three different supply voltages $\mathrm{U}_{\mathrm{d} 1}=U_{\mathrm{dn}}=24 \mathrm{~V}, U_{\mathrm{d} 2}=$ $2 / 3 U_{\mathrm{dn}}=16 \mathrm{~V}$ and $U_{\mathrm{d} 3}=1 / 3 U_{\mathrm{dn}}=8 \mathrm{~V}$. The nominal working point of the motor is marked in the curve as well as the working point for idle run (real). The speeds for rated voltage, which have been obtained by simulations, are equal to, respectively: $n_{0 \mathrm{n}}=4565 \mathrm{rpm}$ and $n_{\mathrm{n}}=3634 \mathrm{rpm}$.

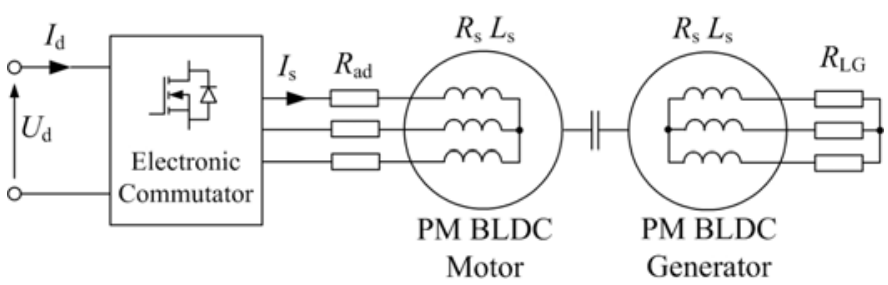

Fig. 8. Schematic diagram of investigated PM BLDC drive.
These values differ from those given by the motor catalogue less than 2 and 4 per cent, respectively.

Since some of motor parameters provided by the catalogue are given with much lower accuracy, this result should be pronounced to be very good.

Fig. 10 shows torque-speed characteristics of the motor obtained by measurements of real motor (Fig. 8). The tests have been run for voltages identical to those used during computer simulations.

Since additional inductances are present in main circuit of real motor, these curves demonstrate much greater slopes than those shown in Fig. 9. That is why we have decided to repeat

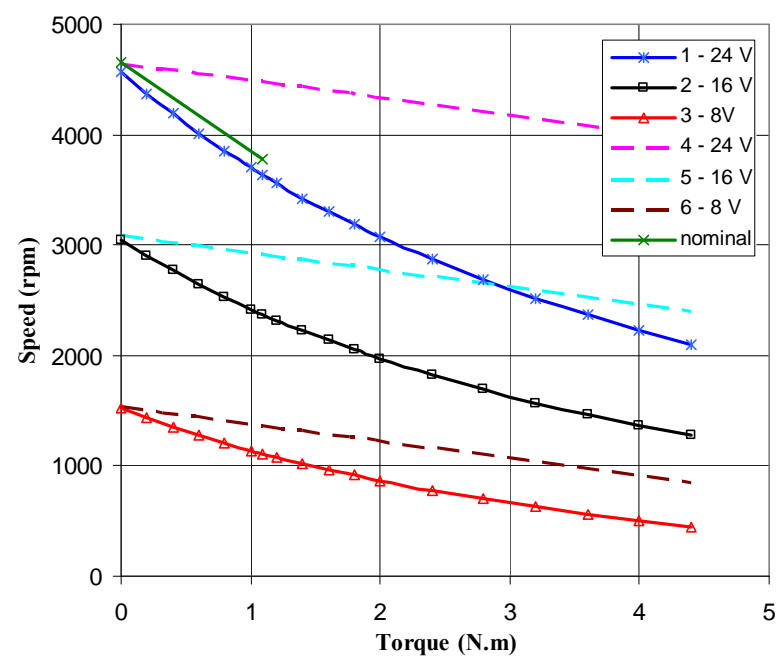

Fig. 9. Torque-speed characteristics of the motor obtained by computer simulations for three supply voltage values $(24 \mathrm{~V}, 16 \mathrm{~V}$ and $8 \mathrm{~V}): 1,2,3$ characteristics for modified constant current model, 4, 5, 6 - characteristics for non-modified constant current model, 7 - nominal working point.

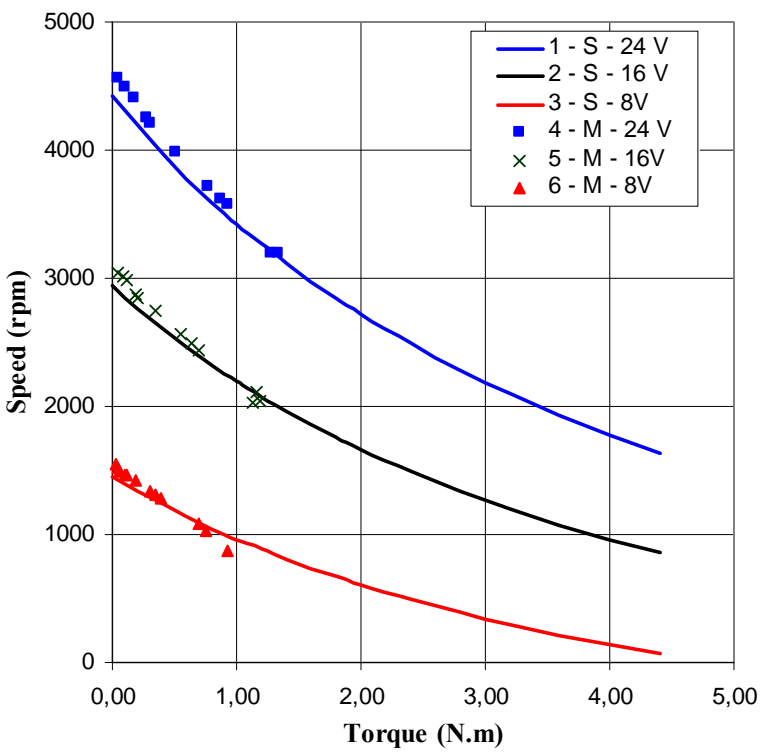

Fig. 10. Torque-speed characteristics of the motor obtained by computer simulations of modified model $(1,2,3)$ for three supply voltage values $(24 \mathrm{~V}$, $16 \mathrm{~V}$ and $8 \mathrm{~V}$ ), with additional resistance $R_{\mathrm{ad}}=0,04 \Omega$ and additional inductance $L_{\mathrm{ad}}=0,01 \mathrm{mH}$; measurement results $(4,5,6)$ obtained for identical voltages. 
simulation tests, but with taking into account additional inductances in model shown in Fig. 7. The obtained results are marked in Fig. 10. The additional resistance and inductance values have been evaluated as $R_{\mathrm{ad}}=0,04 \Omega$ and $L_{\mathrm{ad}}=0,01$ $\mathrm{mH}$.

\section{FINAL REMARKS AND CONCLUSIONS}

Two constant current model of PM BLDC motors are presented in the paper. In the first model, PM BLDC motor is approximated with dc motor; in the second model, modified constant current model is applied, with additional coefficient which is used to take into account the impact of inductance on torque-speed characteristics. The discussion has been supplemented with measurements carried out on a real standard PM BLDC motor.

The following conclusions have been drawn on the basis of simulation and laboratory tests:

1. Torque-speed characteristics obtained during investigation of constant current functional model (where PM BLDC motor is approximated with dc motor) significantly differ from torque-speed characteristics of real PM BLDC motor. For this reason, this model is not recommended.

2. Torque-speed characteristics obtained during investigation of constant current modified model with additional block accounting for inductance impact are almost identical with torque-speed characteristics of real PM BLDC motor (in the range of rated load torques). This model may therefore be used for computer simulation of systems using PM BLDC motors, provided that analysis of effects occurring in the machine or electronic commutator is not necessary [10].

\section{ACKNOWLEDGMENT}

The research has been conducted within the framework of the grant No. 5142/B/T02/2011/40.

\section{REFERENCES}

[1] A. Bodora, T. Biskup, and A. Domoracki, "Two-zones drive of small electric vehicle with BLDC motors," Electrotechnical News, vol. 12, pp 42-47, 2010 (in Polish).

[2] A. Domoracki, and K. Krykowski, BLDC drives - the classical control strategies. Technical conferences of Problems of Electrical Machine and Drive Operation PEMINE, pp. 155 - 159, vol. 72, Katowice, Poland, 2005. (in Polish)

[3] C. Zwyssig, M. Duerr, D. Hassler, and W. J Kolar, An Ultra-HighSpeed, $500000 \mathrm{rpm}, 1 \mathrm{~kW}$ Electrical Drive System. Power Conversion Conference - PCC'07, pp. 1577 - 1583, Nagoja, 2007.

[4] G. Zaleskis, V. Brazis and L. Latkovskis, Estimation of Traction Drive Test Bench with Energy Storage System Operation in Regenerative Braking Mode. Electrical, Control and Communication Engineering. Volume 1, Issue 1, Pages 40-45, ISSN (Online) 2255-9159, ISSN (Print) 2255-9140, DOI: 10.2478/v10314-012-0007-y, January 2013.

[5] J. Hetmańczyk, A. Domoracki, and K. Krykowski, 3.6 kW DC brushless motor control system - the influence of position sensors fault on motion properties. Electrical Drives and Power Electronics - EDPE 2003, pp. 534 - 538, The High Tatras, Slovakia, 2003.

[6] J. R. Hendershot, and T. J. E Miller, Design of brushless permanent magnet motors. Oxford: Magna Physics Publishing and Clarendon Press, 1994.

[7] K. Krykowski, and A. Bodora, Variable Structure Bridge/Half-Bridge Electronic Commutator for PM BLDC Motor Supply. IEEE Power
Electronic and motion Control Conference, pp. 326 - 330, June 20-23, Dubrovnik, Croatia, 2005.

[8] K. Krykowski, and J. Hetmańczyk, The circuital models of PM BLDC, Scientific Bulletin of Silesian University of Technology, s. Electricity, vol.4 (204), pp. 89 - 100, Gliwice, Poland, 2007. (in Polish)

[9] K. Krykowski, J. Hetmańczyk, and D. Makieła, "Impact of windings switching on torque-speed curves of PM BLDC motor," COMPEL - The International Journal for Computation and Mathematics in Electrical and Electronic Engineering, in press.

[10] K. Krykowski, J. Hetmańczyk, T. Stenzel, and M. Sajkowski, Analysis of actuator model with PM BLDC motor used for parallel manipulator. Symposium of Basic Problems of Power Electronics, Electromechanics and Mechatronics PPEEm 2012, pp. 80-83, December 11-13, Gliwice, Poland, 2012.

[11] K. Krykowski, PM BLDC motor in electric drive. Analysis, properties, modeling (in Polish). Gliwice: Silesian University of Technology Press, 2011.

[12] M. A. Rahman, A. Chiba, and T. Fukao, Super high speed electrical machines - summary. Proc. Of Power Engineering Society General Meeting, pp. 1272-1275, vol. 2, June 6-10, Denver, USA 2004.

[13] P. Pillay, and R. Krishnan, Modeling of permanent magnet motor drives. IEEE Transactions on Industrial Electronics, pp. 537-561, vol. 35, No. 4, 1988.

[14] R. Krishnan, Electric Motor Drives, Modeling, Analysis and Control. New Jersey: Prentice Hall, 2001.

[15] T. Glinka, Permanent magnet electrical machines (in Polish). Gliwice: Silesian University of Technology Press, 2002.

[16] T. J. E. Miller, Brushless permanent magnet and reluctance motor drives. Oxford: Clarendon Press, 1989.

[17] www.mathworks.com/help/index.html

[18] Y. Dote, and S. Kinoshita, Brushless servomotors - Fundamental and Applications, Oxford: Clarendon Press, 1990.

[19] Z. Gałuszkiewicz, K. Krykowski, R. Miksiewicz, and J. Hetmańczyk, "High-speed PM BLDC motor," Electrical Review, vol. 86 No. 2, pp. 160-163, 2011.

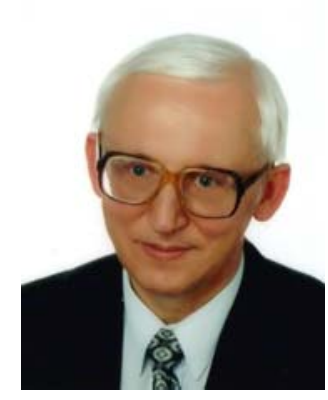

Krzysztof Krykowski received his Ph.D. and D.Sc. degree in electrical engineering from the Silesian University of Technology (Gliwice/Poland) in 1975 and 1988 respectively. He works at Silesian University of Technology as the professor of electrical engineering.

Subjects of his lectures and research are power electronics and electrical drives. He is the author of 2 books and over 100 papers in these areas. Presently he especially interests in modelling, control and supply of high speed brushless motors.

Member of Association of Polish Electrical Engineers SEP, and Polish Society for Theoretical and Applied Electrical Engineering PTETiS.

Postal address: Silesian University of Technology, Faculty of Electrical Engineering, Department of Power Electronics, Electrical Drives and Robotics Bolesława Krzywoustego 2, 44-100 Gliwice, Poland.

e-mail: Krzysztof.Krykowski@polsl.pl

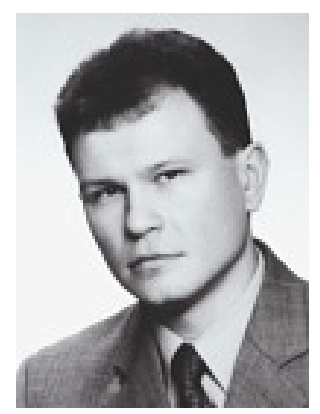

Janusz Hetmańczyk received M.Sc. and $\mathrm{Ph} . \mathrm{D}$. degrees in electrical engineering from Faculty of Electrical Engineering, Silesian University of Technology in 1998 and 2006, respectively. He works in department of Power Electronics, Electrical Drives and Robotics.

$\mathrm{He}$ is an author and co-author of close to 50 scientific papers. His scientific activities involve low power drives, electric vehicles especially modelling, simulation, control and applications of brushless DC motors.

Postal address: Silesian University of Technology, Faculty of Electrical Engineering, Department of Power Electronics, Electrical Drives and Robotics, Bolesława Krzywoustego 2, 44-100 Gliwice, Poland. e-mail: Janusz.Hetmanczyk@polsl.pl 